\title{
NKG2D Enhances Double-Negative T Cell Regulation of B Cells
}

\author{
Shi-hua $\mathrm{Hu}^{1}$, Long-hui Zhang ${ }^{1}$, Jie Gao ${ }^{1}$, Jing-heng Guo ${ }^{1}$, Xiao-dong Xun ${ }^{1}$, Xiao Xiang ${ }^{1}$, \\ Qian Cheng ${ }^{1,2}$, Zhao $\mathrm{Li}^{1,2 *}$ and Ji-ye Zhu ${ }^{1,2 *}$ \\ ${ }^{1}$ Department of Hepatobiliary Surgery, Peking University Organ Transplantation Institute, Peking University People's Hospital, \\ Beijing, China, 2 Peking University Centre of Liver Cancer Diagnosis and Treatment, Beijing Key Surgical Basic Research \\ Laboratory of Liver Cirrhosis and Liver Cancer, Peking University People's Hospital, Beijing, China
}

OPEN ACCESS

Edited by:

Lesley Ann Smyth, University of East London,

United Kingdom

Reviewed by:

Fang Zhou,

CAS Lamvac Biotech Co., Ltd., China

Giang Tran,

University of New South Wales,

Australia

*Correspondence:

Zhao Li

goodlizhao@sina.com

Ji-ye Zhu

gandanwk@vip.sina.com

Specialty section:

This article was submitted to Immunological Tolerance and Regulation,

a section of the journal

Frontiers in Immunology

Received: 08 January 2021 Accepted: 02 June 2021

Published: 16 June 2021

Citation:

Hu S-h, Zhang L-h, Gao J, Guo J-h, Xun X-d, Xiang $X$,

Cheng Q, Li Z and Zhu J-y (2021)

NKG2D Enhances Double-Negative

$T$ Cell Regulation of $B$ Cells.

Front. Immunol. 12:650788.

doi: 10.3389/fimmu.2021.650788
Numerous studies reported a small subpopulation of $\mathrm{TCR} \alpha \beta^{+} \mathrm{CD} 4^{-} \mathrm{CD} 8^{-}$(doublenegative) $T$ cells that exert regulatory functions in the peripheral lymphocyte population. However, the origin of these double-negative T (DNT) cells is controversial. Some researchers reported that DNT cells originated from the thymus, and others argued that these cells are derived from peripheral immune induction. We report a possible mechanism for the induction of nonregulatory $\mathrm{CD}^{+} \mathrm{T}$ cells to become regulatory double-negative $T$ (iDNT) cells in vitro. We found that immature bone marrow dendritic cells $\left(\mathrm{CD} 86^{+} \mathrm{MHC}-\mathrm{Il}^{-} \mathrm{DCs}\right)$, rather than mature DCs $\left(\mathrm{CD}^{\circ} 6^{+} \mathrm{MHC}-\mathrm{II}^{+}\right)$, induced high levels of iDNT cells. The addition of an anti-MHC-II antibody to the CD86 ${ }^{+} \mathrm{MHC}-\mathrm{II}^{+} \mathrm{DC}$ group significantly increased induction. These iDNT cells promoted B cell apoptosis and inhibited B cell proliferation and plasma cell formation. A subgroup of iDNT cells expressed NKG2D. Compared to NKG2D- iDNT cells, NKG2D+ iDNT cells released more granzyme B to enhance $B$ cell regulation. This enhancement may function via NKG2D ligands expressed on B cells following lipopolysaccharide stimulation. These results demonstrate that $\mathrm{MHC}-\|$ impedes induction, and iDNT cells may be MHC independent. NKG2D expression on iDNT cells enhanced the regulatory function of these cells. Our findings elucidate one possible mechanism of the induction of peripheral immune tolerance and provide a potential treatment for chronic allograft rejection in the future.

Keywords: CD4-CD8- double-negative T cells, TCR $\alpha \beta$, MHC class II, NKG2D, dendritic cells, CD4+ ${ }^{+}$cells, B cells

\section{INTRODUCTION}

Approximately two decades ago, a novel subset of TCR $\alpha \beta^{+} \mathrm{CD}^{+} \mathrm{CD}^{-} \mathrm{CD} 8^{-}$double-negative $\mathrm{T}$ (DNT) cells was identified in the peripheral lymphoid tissues of normal rodents and humans (1). These DNT cells lack the expression of CD4, CD8 and NK1.1 but express TCR $\alpha \beta$ and CD3. Although these cells account for only $1 \%$ to $5 \%$ of the peripheral lymphocyte population, they play an important role in the induction of peripheral immune tolerance and participate in the regulation of inflammatory responses. For example, DNT cells significantly prolong allo- and xenogeneic graft survival, alleviate graft-versus-host disease, and prevent autoimmune diseases and cancer in an antigen-specific manner (2-8). Nonetheless, the origin of these DNT cells is controversial. 
Some researchers reported that DNT cells originated from the thymus (9), and others argued that these cells are derived from peripheral immune induction (10).

Previous researchers reported that nonregulatory $\mathrm{CD} 4^{+} \mathrm{T}$ cells might be induced to become DNT cells in vitro (11). These ex vivo-induced DNT cells (iDNT cells) exhibit a phenotype that is consistent with the physiological DNT cell phenotype and perform regulatory functions, including antigen-specific inhibition of $\mathrm{T}$ cell- and $\mathrm{B}$ cell-mediated immune responses (11-13). Nevertheless, the mechanisms of induction are not well understood.

Natural killer group 2-member D (NKG2D) is an activating receptor that is commonly expressed on all NK cells. NKG2D is also expressed on some subsets of NKT cells, activated murine $\mathrm{CD}^{+} \mathrm{T}$ cells, activated human $\mathrm{CD}^{+} \mathrm{T}$ cells, $\gamma \delta \mathrm{T}$ cells, murine macrophages, and a minor population of human $\mathrm{CD}^{+} \mathrm{T}$ cells (14-19). NKG2D is a fundamental receptor that binds to a variety of stress ligands, including ULBP and human Rae1 in humans. Rae1, H60 and Mult1 are the ligands of NKG2D in mice (20). The binding of NKG2D to its ligands induces NK cells to secrete cytokines that promote killing activity. NKG2D on $\mathrm{CD}^{+} \mathrm{T}$ cells acts as a costimulatory factor, and its binding leads to effector and memory $\mathrm{T}$ cell formation $(21,22)$. However, little is known about whether iDNT cells express NKG2D and bind to NKG2D ligands.

The present study examined the possible mechanisms of the induction of nonregulatory $\mathrm{CD}^{+} \mathrm{T}$ cells to become iDNT cells in vitro. We also examined the regulatory effects of iDNT cells on $\mathrm{B}$ cells and the mechanism of iDNT cell regulation of B cells. Our results suggested that immature bone marrow dendritic cells $\left(\mathrm{CD} 86^{+} \mathrm{MHC}^{-\mathrm{II}^{-}} \mathrm{DCs}\right)$, rather than mature bone marrow DCs $\left(\mathrm{CD} 86^{+} \mathrm{MHC}-\mathrm{II}^{+}\right)$, induce iDNT cells. MHC-II impedes induction, and iDNT cells may be MHC independent. We also found that a group of iDNT cells expresses NKG2D. These $\mathrm{NKG}_{2} \mathrm{D}^{+}$iDNT cells had a stronger ability to regulate B cells via NKG2D ligands than cells that did not express NKG2D.

\section{MATERIALS AND METHODS}

\section{Mice}

Male 6-week-old C57BL/6 $\left(\mathrm{H}-2^{\mathrm{b}}\right)$ and BALB/c $\left(\mathrm{H}-2^{\mathrm{d}}\right)$ mice were purchased from Beijing Vital River Laboratory Animal Technology Co., Ltd. and maintained in specific pathogen-free animal facilities of Peking University People's Hospital. The Peking University People's Hospital Animal Ethics and Experimental Committee approved all animal experiments.

\section{Reagents and Flow Cytometry}

Lipopolysaccharide (LPS) was obtained from Sigma (USA, California). Recombinant mouse granulocyte-macrophage colony-stimulating factor (GM-CSF), IL-2 and IL-4 were obtained from PeproTech (USA). A quantitative polymerase chain reaction (q-PCR) kit was purchased from Invitrogen. To analyze single-cell suspensions of lymphocytes, antibodies against CD3 (17A2), CD4 (GK1.5), CD8 (53-6.7), CD127 (A7R34), TCR $\beta$ (H57-597), and CD25 (7D4) were used to distinguish T cells.
Antibodies against CD19, IgM and IgD were used to sort naïve B cells. An anti-CD40 antibody was used to stimulate naïve B cells (BioLegend, USA). Anti-CD86 (GL7), anti-MHC-II (I-A/I-E), and anti-CD11c (N418) antibodies were used to sort mature bone marrow DCs. Anti-CD3 (17A2), anti-CD4 (GK1.5), anti-TCR $\beta$ (H57-597) and anti-NKG2D (CX5) antibodies were used to characterize iDNT cells. Anti-Rae1 (186107), anti-ULBP-1/ MULT-1 (FAB2588R-100UG) antibodies were used to detect the protein expression of Rae1 and Mult1 on B cells.

\section{Purification and Induction of Bone Marrow DCs}

DCs isolated from mouse bone marrow were induced according to the methods of Lutz (23). Briefly, red blood cells were lysed, and bone marrow cells from male BALB/c mice were cultured with recombinant GM-CSF $(10 \mathrm{ng} / \mathrm{ml})$ and recombinant $\mathrm{IL}-4$ $(10 \mathrm{ng} / \mathrm{ml})$ and treated with LPS $(10 \mu \mathrm{g} / \mathrm{ml})$ on day 6 . Bone marrow DCs were harvested on day 7 via positive selection for CD11c, CD86 and/or MHC-II.

\section{Preparation of iDNT Cells In Vitro}

iDNT cells were prepared as previously described with minor modifications (11). Briefly, $\mathrm{CD} 4^{+} \mathrm{CD} 127^{\text {hi }} \mathrm{CD} 25^{-} \mathrm{T}$ cells were obtained from the spleens of male $\mathrm{C} 57 \mathrm{BL} / 6$ mice via flow cytometry sorting. The sorted $\mathrm{T}$ cells were cocultured with bone marrow $\mathrm{DC}$ from $\mathrm{BALB} / \mathrm{c}$ mice at a ratio of $1 \times 10^{5} \mathrm{~T}$ cells to $2.5 \times 10^{4}$ DCs for up to 7 days in 96-well round-bottom plates in complete RPMI 1640 (RPMI medium containing 10\% FBS, $100 \mathrm{IU} / \mathrm{ml}$ penicillin, $100 \mu \mathrm{g} / \mathrm{mL}$ streptomycin and $2 \mathrm{mM}$ L-glutamine). Different concentrations of recombinant IL-2 (0, $50 \mathrm{ng} / \mathrm{mL}, 100 \mathrm{ng} / \mathrm{mL}$ or $200 \mathrm{ng} / \mathrm{mL}$ ) were added to the mixed lymphocyte reaction (MLR) to assess the induction effect of IL-2. TCR $\alpha \beta^{+} \mathrm{CD} 3^{+} \mathrm{CD} 4^{-} \mathrm{CD} 8^{-} \mathrm{NKG}^{-} \mathrm{D}^{+}$and/or TCR $\alpha \beta^{+}$ $\mathrm{CD} 3^{+} \mathrm{CD} 4^{-} \mathrm{CD} 8^{-} \mathrm{NKG}^{-} \mathrm{D}^{-}$iDNT cells were selected using flow cytometry sorting.

\section{Evaluation of the Effects of iDNT Cells on Naïve B Cells In Vitro}

To evaluate the effects of iDNT cells on B cells, freshly sorted $\mathrm{NKG}_{2} \mathrm{D}^{+}$or NKG2D iDNT cells were cocultured with different ratios of B cells for 18 hours with $5 \mathrm{ng} / \mathrm{mL}$ LPS in B cell medium (RPMI medium containing 10\% FBS, $100 \mathrm{IU} / \mathrm{ml}$ penicillin, $100 \mu \mathrm{g} /$ $\mathrm{mL}$ streptomycin, $2 \mathrm{mM}$ L-glutamine, and $2 \mu \mathrm{g} / \mathrm{mL}$ anti-CD40 antibody). Apoptosis kits (Invitrogen, Catalog\# V13241) were used to detect B cell apoptosis. The EdU Flow Cytometry Assay Kit (Invitrogen, Catalog\# C10424) was used to analyze the proliferation of $\mathrm{B}$ cells in these mixed lymphocyte reactions. To observe the effects of $\mathrm{NKG}_{2} \mathrm{D}^{+}$or NKG2D ${ }^{-}$iDNT cells on naïve B cells and plasma cells, $10 \mathrm{ng} / \mathrm{mL}$ LPS was added to the B cell medium for 2 days. Anti-B220, anti-CD138, anti-CD86 and annexin V antibodies were used to analyze the mixed lymphocyte reaction.

\section{q-PCR}

Total RNA was extracted from freshly sorted NKG2D ${ }^{+}$iDNT cells or NKG2D ${ }^{-}$iDNT cells using TRIzol reagent (Invitrogen, Catalog\# 15596018) according to a standard protocol. The extracted RNA 
was reverse transcribed into CDNA, and q-PCR was performed to detect the expression of Inf- $\gamma$, perforin, $I L-17 a, I L-2, I L-4, I L-10$, $I L-21$ and granzyme $b$. The following primers were used for q-PCR: Inf- $\gamma$ (forward: ATGAACGCTACACACTGCATC, reverse: CCATCCTTTTGCCAGTTCCTC), perforin (forward: AGCACAAGTTCGTGCCAGG, reverse: GCGTCTCTC ATTAGGGAGTTTTT), IL-17a (forward: TTTAACTCC CTTGGCGCAAAA, reverse: CTTTCCCTCCGCATTGACAC), IL-2 (forward: TGAGCAGGATGGAGAATTACAGG, reverse: GTCCAAGTTCATCTTCTAGGCAC), IL-4 (forward: GGTCTCAACCCCCAGCTAGT, reverse: GCCGATGATCTCT
CTCAAGTGAT), IL-10 (forward: GCTCTTACTGACT GGCATGAG, reverse: CGCAGCTCTAGGAGCATGTG), IL-21 (forward: GGACCCTTGTCTGTCTGGTAG, reverse: TGTGGAGCTGATAGAAGTTCAGG), and granzyme $b$ (forward: CCACTCTCGACCCTACATGG, reverse: GGCCCCC AAAGTGACATTTATT). RNA extracted from B cells stimulated with LPS $(10 \mu \mathrm{g} / \mathrm{mL})$ in B cell medium for 12 hours was also reverse transcribed to detect $H 60$ (forward: CTGAGCTATC TGGGGACCATAC, reverse: AGTCTTTCCATTCAC TGAGCAC), Rae1 (forward: TTTGGGAGCACAA CCACAGAT, reverse: TAAAGTTGGCGGGCTGAAAGA),
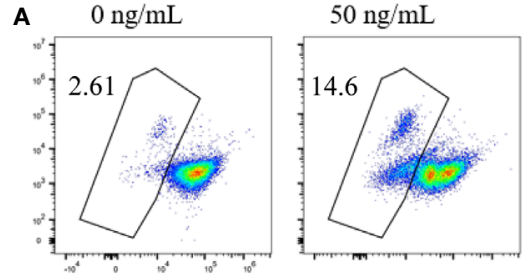

$100 \mathrm{ng} / \mathrm{mL}$

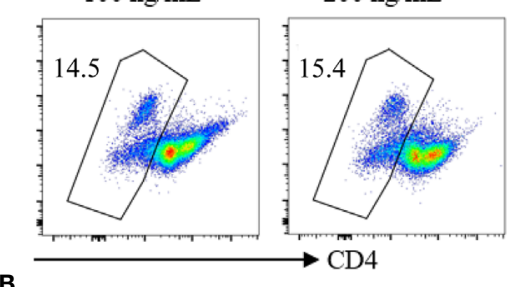

B

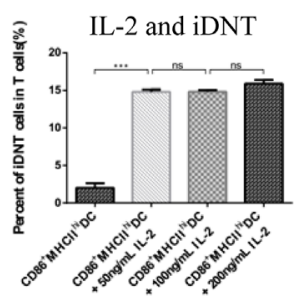

F

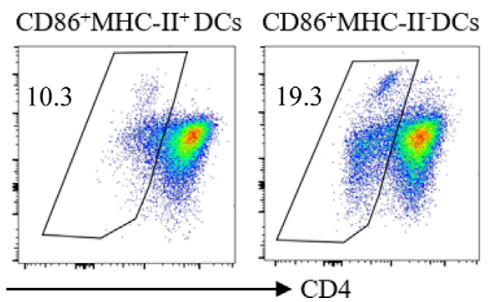

$\mathrm{CD}^{2} 6^{+} \mathrm{MHC}-\mathrm{II}^{+} \mathrm{DCs}+$ $20 \mu \mathrm{g} / \mathrm{mL}$ anti-MHC-II Ab

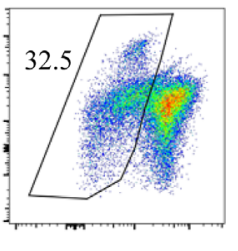

C
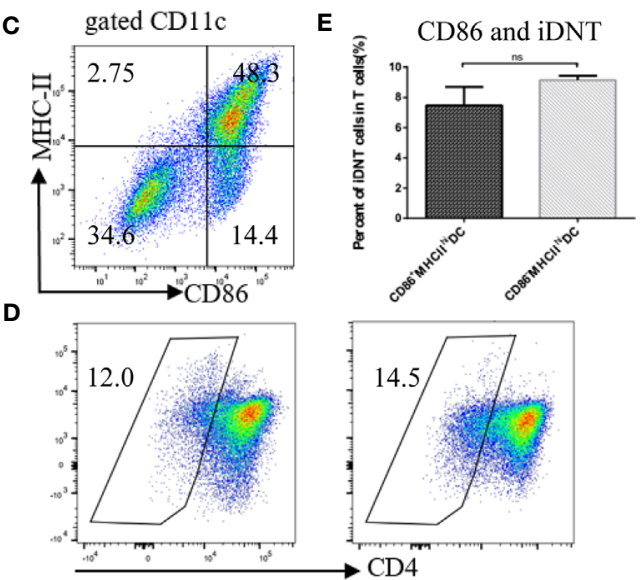

FIGURE 1 | MHC class II impedes the induction of nonregulatory CD4 ${ }^{+} \mathrm{T}$ cells into iDNT cells. (A, B) Freshly sorted CD4 ${ }^{+} \mathrm{CD} 127^{\text {hi }} \mathrm{CD} 25^{-} \mathrm{T}$ cells were cocultured with mature bone marrow dendritic cells (CD86 ${ }^{-} \mathrm{MHC}-\|^{+} \mathrm{DCs}$ ) at a ratio of $1 \times 10^{5} \mathrm{~T}$ cells to $2.5 \times 10^{4} \mathrm{DCs}$ for up to 7 days in 96 -well round-bottom plates in complete RPMI 1640. Different concentrations of IL-2 (0, $50 \mathrm{ng} / \mathrm{mL}, 100 \mathrm{ng} / \mathrm{mL}$ or $200 \mathrm{ng} / \mathrm{mL})$ were added to the culture system. TCR $\alpha \beta^{+} \mathrm{CD} 3^{+} \mathrm{CD} 4^{-} \mathrm{CD} 8^{-} \mathrm{iDNT}^{-} \mathrm{cells}$ were analyzed to evaluate the influence of IL-2 on induction. (A) The TCR $\alpha \beta^{+} \mathrm{CD} 3^{+} \mathrm{CD} 4^{-} \mathrm{CD} 8^{-}$cell population is gated. Representative flow cytometry profiles of different concentrations of IL-2 (0,50 ng/mL, $100 \mathrm{ng} / \mathrm{mL}$ or $200 \mathrm{ng} / \mathrm{mL})$. (B) The bar graphs are representative of three independent experiments. (C) Representative data of the use of anti-CD86 and anti-MHC-II antibodies to divide bone marrow DCs into two subgroups: mature DCs $\left(\mathrm{CD} 86^{+} \mathrm{MHC}-\mathrm{II}^{+}\right)$and immature $\mathrm{DC}$ (CD86 ${ }^{-} \mathrm{MHC}-\mathrm{II}^{+}$,

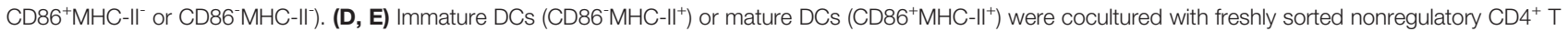
cells. IL-2 (50 ng/mL) was added to the culture system. iDNT cells were analyzed to evaluate the influence of CD86 on induction. (D) Representative flow cytometry profiles of these two mixed lymphocyte reactions. (E) The bar graphs are representative of three independent experiments. $(\mathbf{F}$, $\mathbf{G})\left(\mathrm{Immature} \mathrm{DC}\right.$ ( $\left(\mathrm{CD} 86^{+} \mathrm{MHC}-\mathrm{II}^{-}\right)$, mature DCs $\left(\mathrm{CD} 6^{+} \mathrm{MHC}-\mathrm{II}^{+}\right)$or mature DCs with anti-MHC-II antibody $(20 \mu \mathrm{g} / \mathrm{mL})$ were cocultured with freshly sorted nonregulatory CD4 ${ }^{+} \mathrm{T}$ cells. IL-2 $(50 \mathrm{ng} / \mathrm{mL})$ was added to the culture system. iDNT cells were analyzed to evaluate the influence of MHC class II on induction. (F) Representative flow cytometry profiles of these three mixed lymphocyte reactions. (G) The bar graphs are representative of three independent experiments. Student's $t$-test was used to compare two independent variables (ns, not significant, ${ }^{\star \star} p<0.01$, and ${ }^{\star \star \star} p<0.001$ ). 
Mult1 (forward: CTGCCAGTAACAAGGTCCTTTC, reverse: GCTGTTCCTATGAGCACCAATG) and GAPDH (forward: AGGTCGGTGTGAACGGATTTG, reverse: TGTAGACC ATGTAGTTGAGGTCA) using q-PCR following the standard protocol provided by the manufacturer.

\section{Statistical Analysis}

All statistical analyses were performed using GraphPad v6.0 software. Data are presented as the means \pm standard deviation. Student's $t$-test was used to compare two independent variables (ns, not significant, ${ }^{*} p<0.05,{ }^{* *} p<0.01$, and ${ }^{* *} p<0.001$ ).

\section{RESULTS}

\section{MHC-II Impedes the Induction of $\mathrm{CD}^{+}{ }^{+} \mathrm{CD} 127^{\text {hi }} \mathrm{CD}^{-} 5^{-} \mathrm{T}$ Cells Into iDNT Cells}

To examine the factors that influence the induction of nonregulatory $\mathrm{CD} 4^{+} \mathrm{T}$ cells into $\mathrm{TCR} \alpha \beta^{+} \mathrm{CD} 4^{-} \mathrm{CD} 8^{-} \mathrm{DNT}$ cells, we added different concentrations of IL-2 to a culture system
(Figures 1A, B). We found that the addition of $50 \mathrm{ng} / \mathrm{mL}, 100$ $\mathrm{ng} / \mathrm{mL}$ or $200 \mathrm{ng} / \mathrm{mL}$ IL-2 greatly affected the number of iDNT cells compared to no IL-2 treatment (Figure 1B). To further examine whether immature bone marrow DCs also induced this process, CD86 ${ }^{-} \mathrm{MHC}^{-\mathrm{II}^{+}} \mathrm{DCs}$ were cocultured with nonregulatory $\mathrm{CD} 4^{+} \mathrm{T}$ cells (Figure 1C). We found no significant difference between $\mathrm{CD}^{+} 6^{+} \mathrm{MHC}-\mathrm{II}^{+}$DCs and CD86 ${ }^{-} \mathrm{MC}^{-\mathrm{II}^{+}}$DCs (Figure 1D). CD86 ${ }^{+} \mathrm{MHC}^{-\mathrm{II}^{\mathrm{lo}}-\mathrm{D}}$ DCs were also used. We found that low or no $\mathrm{MHC}$ expression on $\mathrm{CD} 86^{+} \mathrm{DCs}$ influenced the induction process (Figures 1E, F), and the addition of an anti-MHC-II antibody to the $\mathrm{CD} 86^{+} \mathrm{MHC}-\mathrm{II}^{+} \mathrm{DC}$ group significantly increased the number of iDNT cells in the group compared to the numbers in other groups (Figures 1E-G).

\section{IL-2 and MHC-II May Regulate NKG2D Expression on iDNT Cells}

After the successful induction of iDNT cells, we found that some of these cells expressed NKG2D molecules (Figure 2A). Different concentrations of IL-2 and immature DCs revealed that IL-2 and MHC-II were related to NKG2D expression on iDNT cells
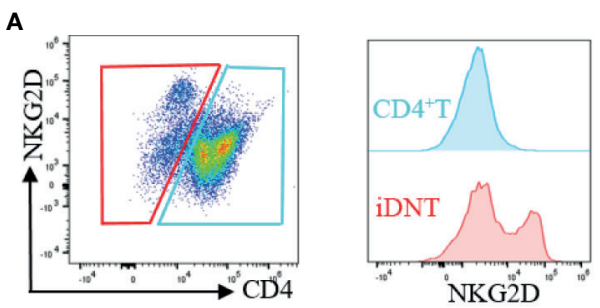

B

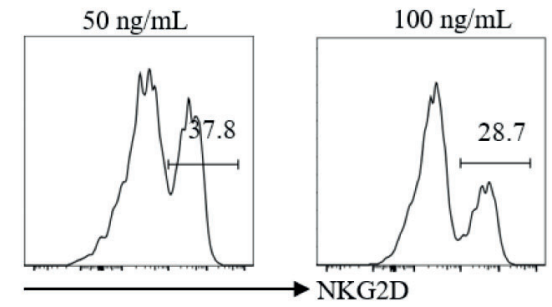

D

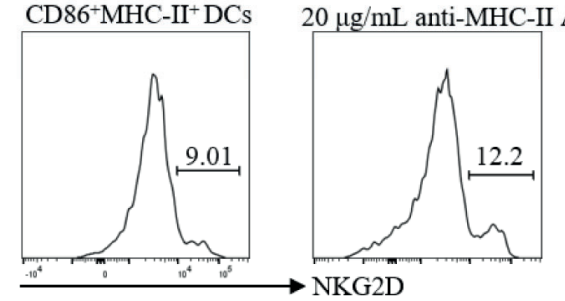

$200 \mathrm{ng} / \mathrm{mL}$
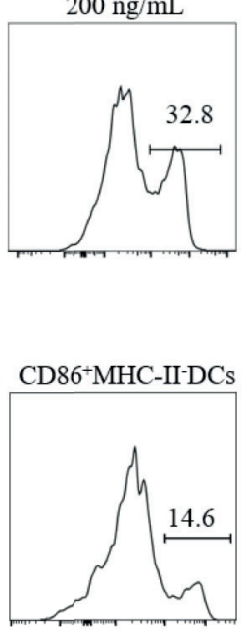

C
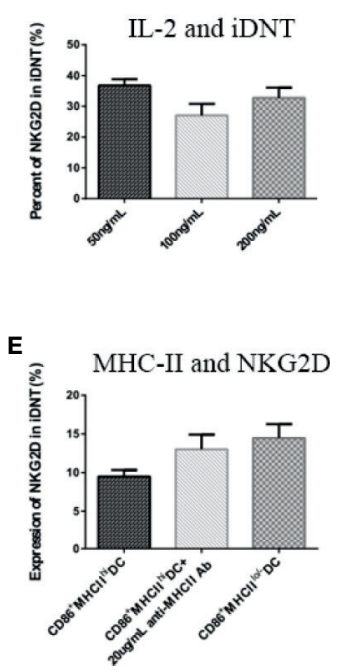

FIGURE 2 | IL-2 and MHC-II may regulate NKG2D expression on iDNT cells. (A) A representative experiment shows that a group of iDNT cells expressed NKG2D molecules. (B, C) Nonregulatory CD4 ${ }^{+} \mathrm{T}$ cells were cocultured with mature bone marrow dendritic cells $\left(\mathrm{CD} 86^{-} \mathrm{MHC}-\mathrm{II}^{+} \mathrm{DCs}\right) . \mathrm{IL}-2$ (50 $\mathrm{ng} / \mathrm{mL}, 100 \mathrm{ng} / \mathrm{mL}$ or $200 \mathrm{ng} / \mathrm{mL}$ ) was added to the mixed lymphocyte reaction. After successful induction, the percentage of NKG2D on iDNT cells was detected using flow cytometry. (B) Histograms are representative of NKG2D expression on iDNT cells. (C) The bar graphs are representative of three independent experiments. (D, E) Immature DCs $\left(\mathrm{CD} 86^{+} \mathrm{MHC}-\|^{-}\right)$, mature DCs $\left(\mathrm{CD} 86^{+} \mathrm{MHC}-\|^{+}\right)$or mature DCs with anti-MHC-II antibody $(20 \mu \mathrm{g} / \mathrm{mL})$ were cocultured with nonregulatory $\mathrm{CD} 4^{+} \mathrm{T}$ cells. IL-2 (20 ng/mL) was added to the mixed lymphocyte reaction. After successful induction, the percentage of NKG2D on iDNT cells was analyzed using flow cytometry. (D) Histograms are representative of NKG2D expression on iDNT cells. (E) The bar graphs are representative of three independent experiments. 
(Figures 2B, E). CD86 ${ }^{+}$DCs with low or no MHC expression appeared to induce more iDNT cells than other types of DCs (Figures 2B, E).

\section{NKG2D Enhances iDNT Cell-Mediated Inhibition of B Cell Proliferation and Promotes B Cell Apoptosis}

To study the effects of NKG2D expression on iDNT cells on B cell proliferation and apoptosis, we sorted $\mathrm{NKG}_{2} \mathrm{D}^{+}$and NKG2D iDNT cells and incubated these cells with naïve $B$ cells at a ratio of $4 \times 10^{5} \mathrm{~B}$ cells to $1 \times 10^{5}$ iDNT cells in 96-well round-bottom plates in B cell medium (Figures 3A, B). EdU (10 $\mu \mathrm{M})$ and LPS $(5 \mu \mathrm{g} / \mathrm{mL})$ were added to the medium, and $B$ cell proliferation and apoptosis were detected approximately 18 hours later. We found that $\mathrm{NKG}_{2} \mathrm{D}^{+}$iDNT cells had a stronger ability to inhibit $\mathrm{B}$ cell proliferation and promote $\mathrm{B}$ cell apoptosis than $\mathrm{NKG}^{-} \mathrm{D}^{-}$iDNT cells. NKG2D ${ }^{-}$iDNT cells also suppressed B cell proliferation and promoted B cell apoptosis (Figures 3C, D).

\section{NKG2D Enhances iDNT Cell-Mediated Inhibition of B Cell Differentiation Into Plasma Cells In Vitro}

To further evaluate the function of NKG2D molecules, we extended the incubation time to 2 days, added a higher concentration of LPS $(10 \mu \mathrm{g} / \mathrm{mL})$ to the medium and reduced the number of B cells to a gradient ratio of $4 \times 10^{5} \mathrm{~B}$ cells to $0.4 \times 10^{5}$, $0.2 \times 10^{5}$ or $0.1 \times 10^{5}$ iDNT cells. We analyzed B cell differentiation and found that $\mathrm{NKG}^{+} \mathrm{D}^{+} \mathrm{iDNT}$ cells had a stronger inhibitory ability than NKG2D- iDNT cells at all ratios (Figures 4A, B). We also detected $\mathrm{B}$ cell apoptosis and found that $\mathrm{NKG}^{2} \mathrm{D}^{+}$iDNT cells promoted more B cell apoptosis than $\mathrm{NKG}^{-} \mathrm{D}^{-}$iDNT cells at all ratios. However, the difference in apoptosis between groups became less obvious as the ratio decreased (Figures 4C, D). We further evaluated CD86 to detect the level of activated B cells. As expected, iDNT cells suppressed B cell activation, and NKG2D ${ }^{+}$ iDNT cells had a stronger inhibitory capability than NKG2D iDNT cells (Figure 4E).

\section{NKG2D ${ }^{+}$iDNT Cells Express Higher Levels of Granzyme B Than NKG2D- iDNT Cells, and Activated B Cells Express NKG2D Ligands}

To clarify the mechanisms of NKG2D ${ }^{+}$DNT cell inhibition of B cell function, q-PCR was performed to examine granzyme B mRNA levels. We found that NKG2D ${ }^{+}$iDNT cells and NKG2D iDNT cells expressed granzyme $\mathrm{B}$, but $\mathrm{NKG}^{2} \mathrm{D}^{+}$iDNT cells expressed higher levels of granzyme B than NKG2D ${ }^{-}$iDNT cells (Figures 5A, B). This result is consistent with previous studies that showed that iDNT cells also expressed perforin. To determine whether activated B cells expressed NKG2D ligands, we used q-PCR to detect H60, Rae1 and Mult1. We found that activated B cells exhibited Rae1 expression (Figures 5C, D).

\section{DISCUSSION}

During antigen-presenting cell (APC) education, $\mathrm{CD}^{+} \mathrm{T}$ cells are activated, proliferate, differentiate and secrete cytokines.
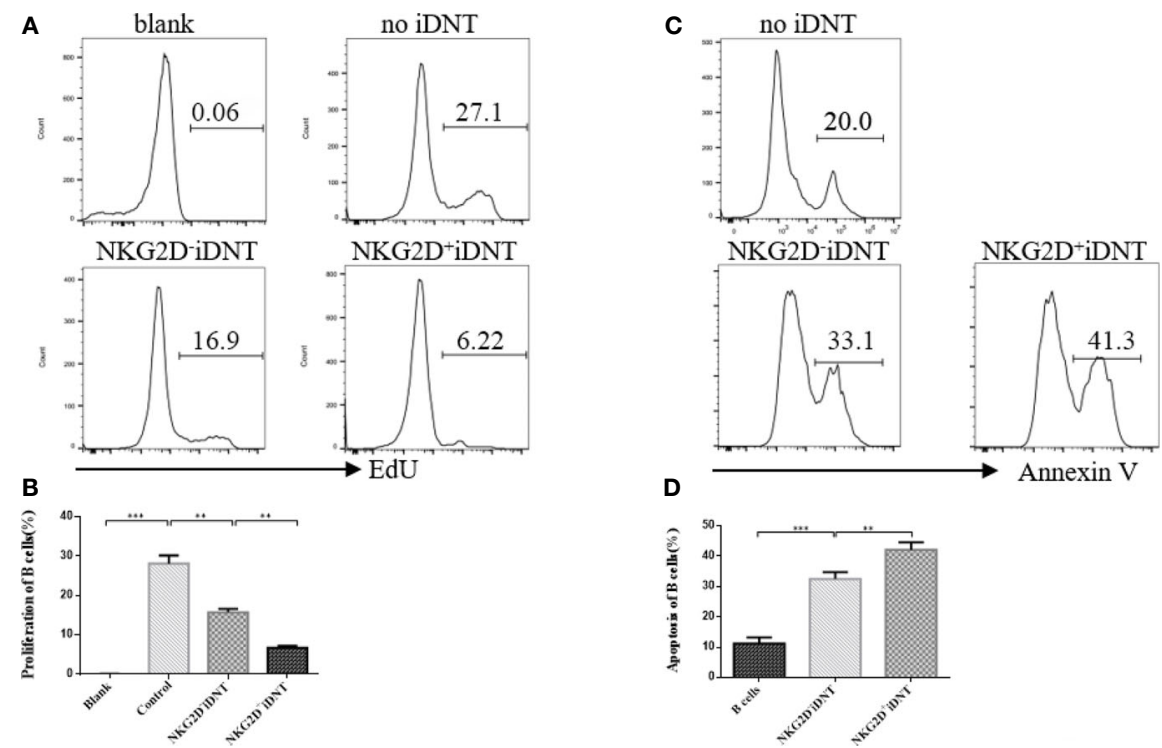

FIGURE 3 | NKG2D enhances iDNT cell-mediated inhibition of B cell proliferation and promotes B cell apoptosis. Naiive B cells were cultured with sorted TCR $\alpha \beta^{+} \mathrm{CD}^{+} \mathrm{CD} 4^{-} \mathrm{CD} 8^{-} \mathrm{NKG}^{2} \mathrm{D}^{+}$or TCR $\alpha \beta^{+} \mathrm{CD} 3^{+} \mathrm{CD} 4^{-} \mathrm{CD} 8^{-} \mathrm{NKG} 2 \mathrm{D}^{-}$iDNT cells at a ratio of $4 \times 10^{5} \mathrm{~B}$ cells to $1 \times 10^{5}$ iDNT cells in $96-$ well round-bottom plates in B cell medium. EdU $(10 \mu \mathrm{M})$ and LPS $(5 \mu \mathrm{g} / \mathrm{mL})$ were added to the medium, and B cell proliferation and apoptosis were detected approximately 18 hours later. (A) Histograms are representative of B cell proliferation. (B) The bar graphs are representative of three independent B-cell proliferation experiments. (C) Histograms are representative of B cell apoptosis. (D) The bar graphs are representative of three independent B-cell apoptosis experiments. Student's $t$-test was used to compare two independent variables $\left({ }^{\star *} p<0.01\right.$ and $\left.{ }^{\star \star *} p<0.001\right)$. 
A
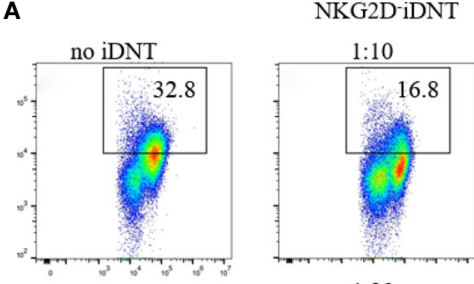

$1: 20$

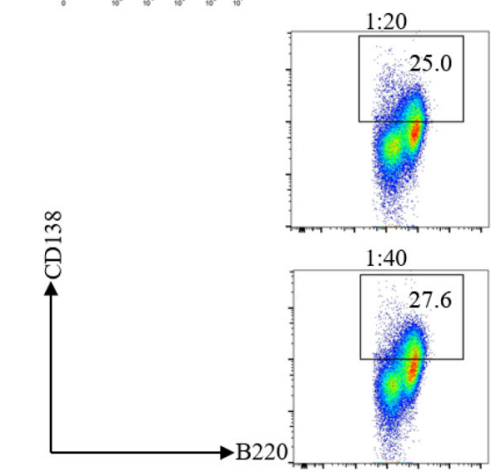

B

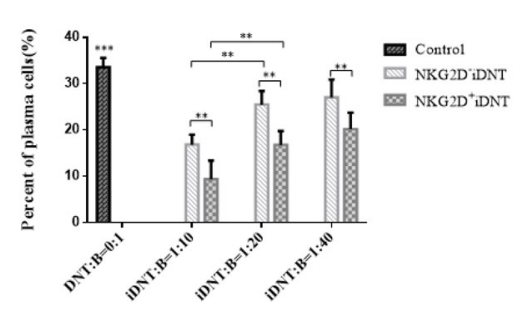

$\mathrm{NKG}_{2} \mathrm{D}^{+} \mathrm{iDNT}$

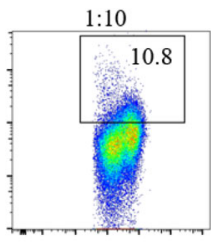

$1: 20$

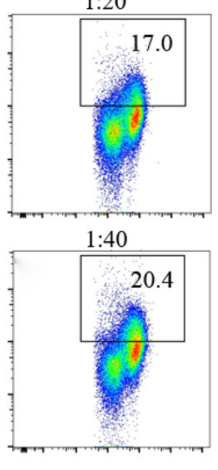

C
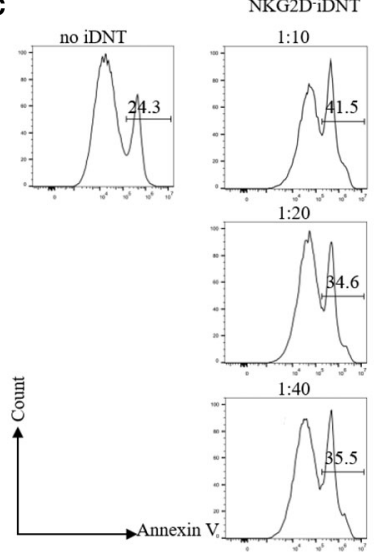

D

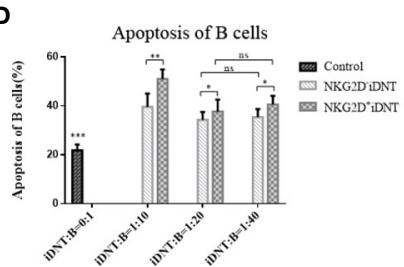

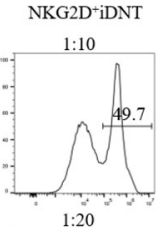
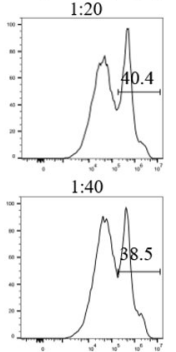

E

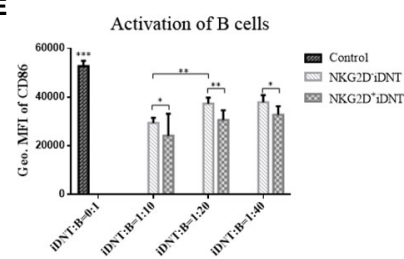

FIGURE 4 | NKG2D enhances iDNT cell-mediated inhibition of B cell differentiation into plasma cells in vitro. Freshly sorted TCR $\alpha \beta^{+} \mathrm{CD} 3^{+} \mathrm{CD} 4^{-} \mathrm{CD} 8^{-} \mathrm{NKG}^{2} \mathrm{D}^{+}$or $^{-}$ TCR $\alpha \beta^{+} \mathrm{CD}^{+} \mathrm{CD}^{-} \mathrm{CD}^{-} \mathrm{NKG} 2 \mathrm{D}^{-}$iDNT cells were incubated with naïve B cells at a gradient ratio of $0.4 \times 10^{5}, 0.2 \times 10^{5}$ or $0.1 \times 10^{5}$ iDNT cells to $4 \times 10^{5} \mathrm{~B}$ cells in $96-$ well round-bottom plates in B cell medium for 2 days. LPS (10 $\mu \mathrm{g} / \mathrm{mL})$ was added to the medium, and we analyzed the activation, differentiation and apoptosis of B cells. (A) Representative flow cytometry profiles of B cell differentiation into plasma cells in vitro. (B) The bar graphs are representative of three independent B-cell differentiation experiments. (C) Histograms are representative of B cell apoptosis at different ratios. (D) The bar graphs are representative of three independent B-cell apoptosis experiments. (E) The bar graphs are representative of three independent B-cell activation experiments. Student's $t$-test was used to compare two independent variables (ns, not significant, ${ }^{\star} p<0.05,{ }^{\star *} p<0.01$, and ${ }^{\star \star *} p<0.001$ ).

All of these immune functions depend on at least two interactive signals between two types of cells: the first signal is derived from TCR-CD3 complexes, which are expressed on the surface of $\mathrm{CD}^{+} \mathrm{T}$ cells and combine with peptide-MHC-II on APCs when activated; the second signal is transduced via CD86/80 molecules, which interact with CD28 molecules. Although several types of cells express MHC-II molecules, DCs are one of the most important APCs expressing this molecule and participating in CD4+ $\mathrm{T}$ cell immune responses. Once $\mathrm{CD} 4^{+} \mathrm{T}$ cells recognize a foreign peptide-MHC-II complex on the plasma membrane of DCs, these cells form TCR-CD3-peptide-MHC-II complexes. CD4 molecules expressed on $\mathrm{CD}^{+}{ }^{+} \mathrm{T}$ cells restructure themselves and extend synapses with MHC-II molecules. Our study found that MHC- $\mathrm{II}^{\mathrm{lo} /-} \mathrm{CD} 86^{+}$DCs, but not MHC$\mathrm{II}^{+} \mathrm{CD} 86^{+} \mathrm{DCs}$, enhanced induction. The addition of an antiMHC-II neutralizing antibody to the $\mathrm{CD} 6^{+} \mathrm{MHC}-\mathrm{II}^{+} \mathrm{DC}$ group significantly increased the number of iDNT cells (Figures 1E, F). These results suggested that CD4 molecules expressed on CD4 ${ }^{+}$ $\mathrm{T}$ cells "disappeared" because of low or nonexistent MHC-II expression. Unlike $\mathrm{CD} 4^{+} \mathrm{T}$ cells binding to liver cell MHC-II molecules to form TCR-CD3-peptide-MHC-II complexes, which are later removed from liver cells in autoimmune hepatitis (24), MHC-II ${ }^{\mathrm{lo} /-} \mathrm{CD} 86^{+}$DCs cannot efficiently contact $\mathrm{CD} 4^{+} \mathrm{T}$ cells. Therefore, CD4 molecules cannot extend synapses with MHC-II molecules and may be gradually lost during the process of cell proliferation supported by a second signal and IL-2. Unlike many receptors that are internalized after continuous stimulation, the CD4 molecule present on the surface of $\mathrm{CD} 4^{+}$ $\mathrm{T}$ cells do not disappear via internalization (11). A recent study reported that concomitant disruption of the CD4 and CD8 genes facilitated the development of DNT cells in the periphery (25). This study used transgenic mice expressing human HLA class II molecules, HLA-DR3 or HLA-DQ8, as test subjects. Because human HLA class II molecules present superantigens more efficiently than murine MHC class II molecules, murine MHC class I and II molecules did not efficiently contact the coreceptors CD4/CD8, which led to CD4 and CD8 gene inactivation. These authors found that this disruption enabled 
A
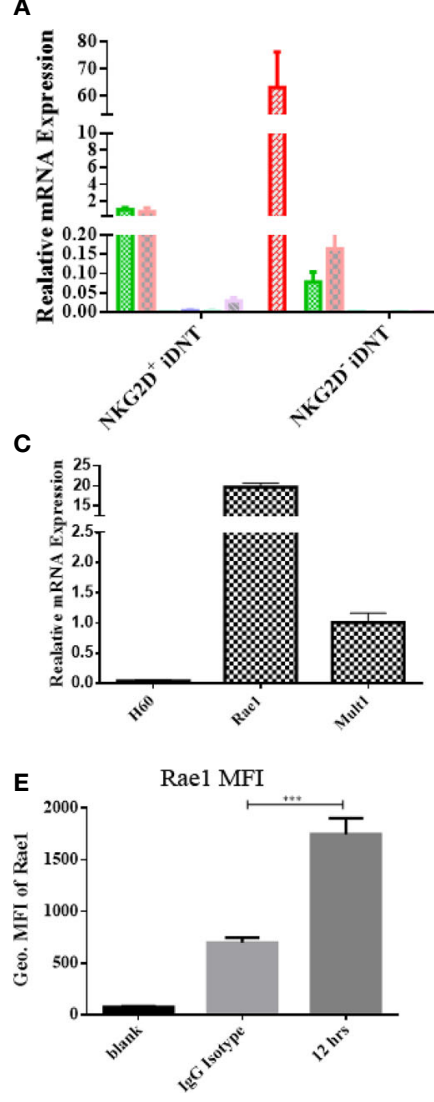

B

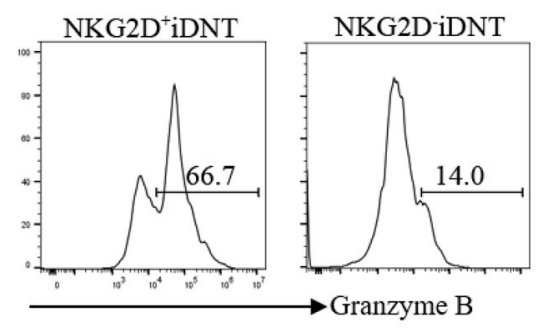

D
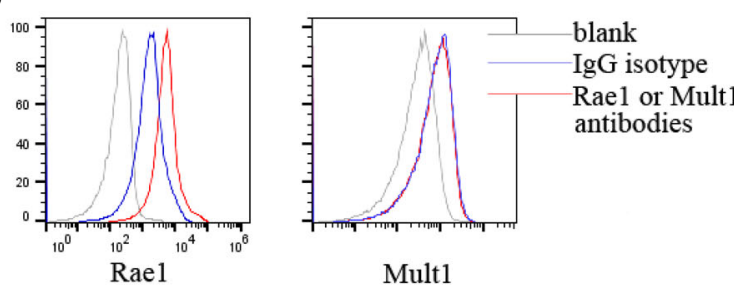

Mult1 MFI

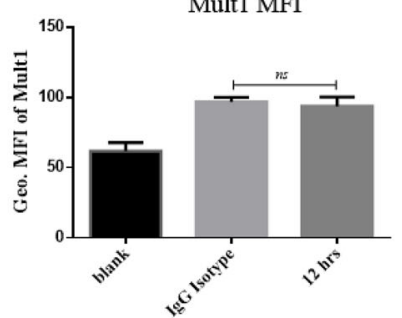

FIGURE 5 | NKG2D+ iDNT cells express higher levels of granzyme B than NKG2D-iDNT cells, and activated B cells express the NKG2D ligand Rae1. (A) Q-PCR was performed to examine granzyme $B$ mRNA levels in freshly sorted TCR $\alpha \beta^{+} C D 3^{+} C D 4^{-} C D 8^{-} N K G 2 D^{+}$and TCR $\alpha \beta^{+} C D 3^{+} C D 4^{-} C D 8^{-} N K G 2 D^{-}$iDNT cells. (B) Granzyme B protein was detected using flow cytometry. (C) Naiive B cells were stimulated with LPS in B cell medium for 12 hours, and q-PCR was performed to examine the expression levels of NKG2D ligands. (D) Naive B cells were stimulated with LPS in B cell medium for 12 hours, and flow cytometry was performed to examine the expression of Rae1 and Mult1. (E) Geometric MFI of Rae1 and Mult1 protein. Student's t-test was used to compare two independent variables (ns, not significant, $\left.{ }^{* *} p<0.001\right)$

the development of DNT cells in the periphery, which is consistent with our findings.

Numerous studies reported that IL-2 was an important factor that promoted robust proliferation of $\mathrm{CD}^{+} \mathrm{T}$ cells after interactions with DCs (26-28). The proliferative ability of treated cells increased gradually with increasing IL-2 concentrations. We also added IL-2 during the process of induction based on our previous studies $(11,12)$, but we found that different amounts of IL-2 did not obviously change induction (Figures 1A, B). Although DCs secrete IL-2 $(27,29,30)$, this secretion is not sufficient. These results indicate that induction requires exogenous IL-2. Critically, anti-CD3 antibodies could not be added to the culture system when inducing CD4 molecule downregulation. This observation is very important because no iDNT cells were observed when anti-CD3 antibodies were added to the mixed lymphocyte reaction (unpublished data).

NKG2D is an activating receptor that is commonly expressed on NK cells. NKG2D is also present on NKT cells, activated CD8 ${ }^{+}$ $\mathrm{T}$ cells, $\gamma \delta \mathrm{T}$ cells, macrophages, and a small subgroup of $\mathrm{CD} 4^{+} \mathrm{T}$ cells $(20,31,32)$. However, little is known about whether
TCR $\alpha \beta^{+} \mathrm{CD}^{+} \mathrm{CD} 4 \mathrm{CD} 8$ - $\mathrm{T}$ cells express NKG2D. Our study found that a group of iDNT cells expressed NKG2D molecules (Figure 2A), and the addition of IL-2 increased induction and NKG2D expression (Figures 2D, E). These results suggested that our iDNT cells were activated after successful induced. This result is similar to the results achieved with IL-2 administration, which activated $\mathrm{CD}^{+} \mathrm{T}$ cells and increased the expression of NKG2D. We do not understand why MHC-II influenced the expression of NKG2D on iDNT cells (Figures 2B, C). However, we will study the mechanism of MHC-II influence on NKG2D in future work.

Activation of the NKG2D receptor promoted NK cell killing activity. This receptor enhanced effector and memory $\mathrm{CD}^{+} \mathrm{T}$ cell formation $(21,22)$. Our study found a group of iDNT cells, NKG2D ${ }^{+}$iDNT cells, that promoted more B cell apoptosis and a stronger inhibition of $\mathrm{B}$ cell proliferation and plasma cell formation than NKG2D- iDNT cells (Figures 3, 4). These results demonstrated that NKG2D enhanced iDNT cellmediated regulation of $\mathrm{B}$ cells. We also determined why $\mathrm{NKG}_{2} \mathrm{D}^{+}$iDNT cells had a stronger regulatory function than $\mathrm{NKG}^{-} \mathrm{D}^{-}$iDNT cells. In this study, we found naïve B cells 
upregulated the protein expression of the NKG2D ligand upon LPS stimulation (Figures 5D, E and Supplementary Figures 1A-C), which is consistent with a previous study that B cells were significantly stained with the NKG2D tetramer after stimulation of splenocytes with ConA or LPS (33). Our study also found that the transcript of Mult1 but not posttranslational protein was detected (Figures 5C-E), indicating the existence of translational or posttranslational regulation. A previous study reported that Mult1 protein was ubiquitinated and degraded under normal conditions (34). However, the degradation and ubiquitination was reduced in response to cell stress (34). In our research, stimulation of naive B cells with LPS for 12 hours might not be sufficient to reduce the degradation and ubiquitination of Mult1 (Supplementary Figures 1D, E). NKG2D ${ }^{+}$iDNT cells and NKG2D ${ }^{-}$iDNT cells expressed granzyme B, and NKG2D ${ }^{+}$ iDNT cells produced more granzyme $\mathrm{B}$ than $\mathrm{NKG}_{2} \mathrm{D}^{+}$iDNT cells (Figures 5A, B). These results suggest that NKG2D ${ }^{-}$iDNT cells are previously activated and secrete some granzyme $\mathrm{B}$. NKG2D activation enhances $\mathrm{NKG}_{2} \mathrm{D}^{+}$iDNT cell regulation via NKG2D ligands on $\mathrm{B}$ cells by inducing an increased release of granzyme B. A recent study showed that the levels of NKG2D ligand expression on splenic B cells increased in mice with aging (35). Another study reported that a small subgroup of mouse B cells, B1a cells, which exhibit NKG2D and NKG2D deficiency, impaired B1a cell development and T cell-independent immune responses (36). All of these reports demonstrate that NKG2D regulates B cell development and effector B cells.

In summary, we showed that nonregulatory $\mathrm{CD} 4^{+} \mathrm{T}$ cells may be induced to become regulatory iDNT cells in vitro. IL-2 promoted the induction process, and MHC-II expression on bone marrow DCs impeded this process. These iDNT cells were activated after successful induction, which promoted B cell apoptosis and inhibited $\mathrm{B}$ cell proliferation and plasma cell formation. A small portion of iDNT cells expressed NKG2D,

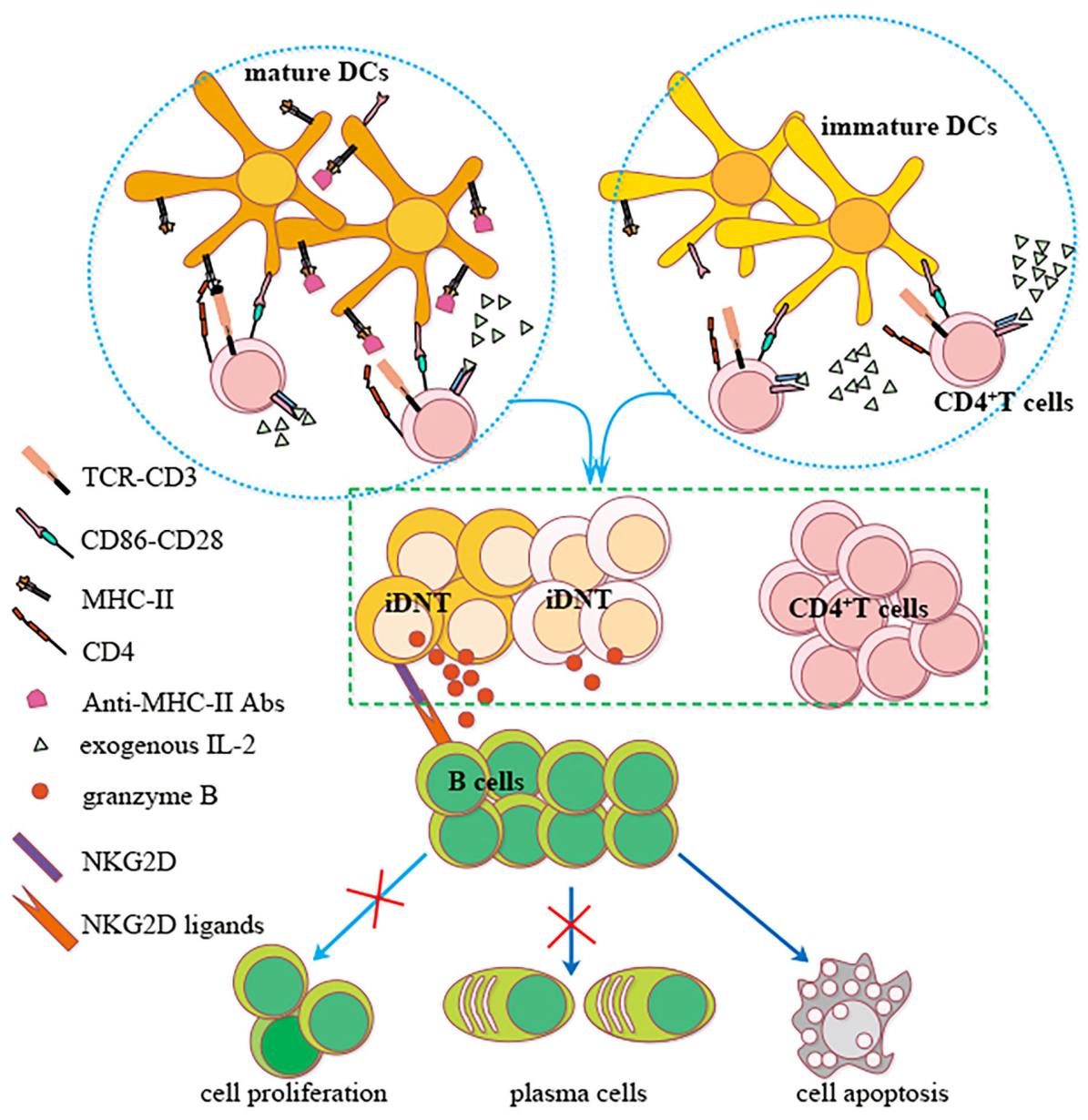

FIGURE 6 | A possible mechanism of nonregulatory CD4 ${ }^{+}$T cells induction into iDNT cells and NKG2D enhancement of iDNT cells regulation of B cells. Nonregulatory $\mathrm{CD}^{+} \mathrm{T}$ cells may be induced to become regulatory iDNT cells in vitro. IL-2 promotes the induction process, and MHC-II expressed on bone marrow DCs impedes this process. These iDNT cells were activated after successful induction, which promoted B cell apoptosis and inhibited B cell proliferation and plasma cell formation. A small portion of iDNT cells express NKG2D, which induces the release of granzyme B to enhance iDNT cell-mediated regulation of B cell functions via the NKG2D ligand Rae1. 
which induced the release of granzyme B to enhance iDNT cellmediated regulation of B cell functions via NKG2D ligands (Figure 6). Therefore, our research provides insight for understanding the mechanism of peripheral immune tolerance and the development of a potential treatment for chronic allograft rejection.

\section{DATA AVAILABILITY STATEMENT}

The raw data supporting the conclusions of this article will be made available by the authors, without undue reservation.

\section{ETHICS STATEMENT}

The animal study was reviewed and approved by Peking University People's Hospital Animal Ethics and Experimental Committee.

\section{AUTHOR CONTRIBUTIONS}

Conceived and designed the experiments: S-hH and J-yZ. Performed the experiments: S-hH. Analyzed the data: L-hZ. Contributed reagents/materials/analysis tools: J-cG, JG, X-dX, QC, and XX. Wrote the article: S-hH and ZL. All authors contributed to the article and approved the submitted version.

\section{REFERENCES}

1. Zhang ZX, Yang L, Young KJ, DuTemple B, Zhang L. Identification of a Previously Unknown Antigen-Specific Regulatory T Cell and Its Mechanism of Suppression. Nat Med (2000) 6:782-9. doi: 10.1038/77513

2. Muller YD, Golshayan D, Ehirchiou D, Wekerle T, Seebach JD, Buehler LH. T Regulatory Cells in Xenotransplantation. Xenotransplantation (2009) 16:1218. doi: 10.1111/j.1399-3089.2009.00531.x

3. Zhang ZX, Ma Y, Wang H, Arp J, Jiang J, Huang X, et al. Double-Negative T Cells, Activated by Xenoantigen, Lyse Autologous B and T Cells Using a Perforin/Granzyme-Dependent, Fas-Fas Ligand-Independent Pathway. J Immunol (2006) 177:6920-9. doi: 10.4049/jimmunol.177.10.6920

4. Lee JB, Kang H, Fang L, D'Souza C, Adeyi O, Zhang L. Developing Allogeneic Double-Negative T Cells as a Novel Off-the-Shelf Adoptive Cellular Therapy for Cancer. Clin Cancer Res (2019) 25:2241-53. doi: 10.1158/1078-0432.CCR18-2291

5. Lee J, Minden MD, Chen WC, Streck E, Chen B, Kang H, et al. Allogeneic Human Double Negative T Cells as a Novel Immunotherapy for Acute Myeloid Leukemia and Its Underlying Mechanisms. Clin Cancer Res (2018) 24:370-82. doi: 10.1158/1078-0432.CCR-17-2228

6. Ford MS, Chen W, Wong S, Li C, Vanama R, Elford AR, et al. PeptideActivated Double-Negative T Cells Can Prevent Autoimmune Type-1 Diabetes Development. Eur J Immunol (2007) 37:2234-41. doi: 10.1002/ eji.200636991

7. Fischer K, Voelkl S, Heymann J, Przybylski GK, Mondal K, Laumer M, et al. Isolation and Characterization of Human Antigen-Specific TCR Alpha Beta+ CD4(-)CD8- Double-Negative Regulatory T Cells. BLOOD (2005) 105:282835. doi: 10.1182/blood-2004-07-2583

8. Chen W, Zhou D, Torrealba JR, Waddell TK, Grant D, Zhang L. Donor Lymphocyte Infusion Induces Long-Term Donor-Specific Cardiac Xenograft Survival Through Activation of Recipient Double-Negative Regulatory $\mathrm{T}$ Cells. J Immunol (2005) 175:3409-16. doi: 10.4049/jimmunol.175.5.3409

9. Collin R, Lombard-Vadnais F, Hillhouse EE, Lebel ME, Chabot-Roy G, Melichar HJ, et al. MHC-Independent Thymic Selection of CD4 and CD8

\section{FUNDING}

This study was supported by grants from the National Natural Science Foundation of China (No. 81570590 and 81502509).

\section{ACKNOWLEDGMENTS}

We thank Dr. Su Li for helping with flow cytometry sorting. Dr. Su Li: Center of Medical and Health Analysis, Peking University, Beijing, China.

\section{SUPPLEMENTARY MATERIAL}

The Supplementary Material for this article can be found online at: https://www.frontiersin.org/articles/10.3389/fimmu.2021. 650788/full\#supplementary-material

Supplementary Figure 1 | The mRNA and Protein expression of Rae1 and Mult1. (A-E) Naïve B cells were stimulated with LPS $(10 \mu \mathrm{g} / \mathrm{mL})$ in B cell medium for $0,6,18$ and 48 hours. Flow cytometry was performed to examine the expression of Rae1 and Mult1. (A) The protein expression of Rae1 was upregulated with the extension of culture time. (B) Geometric MFI of Rae1. (C) Percent of Rae1 protein expression with culture time. (D) The protein expression of Mult1. (E) Geometric MFI of Mult1. Figures 1A-E is an independent experiment. Student's t-test was used to compare two independent variables (ns, not significant, ${ }^{*} \mathrm{p}<0.05$, ${ }^{* *} \mathrm{p}<$ 0.01 , and $\left.{ }^{\star \star *} p<0.001\right)$.

Coreceptor Negative Alphabeta T Cells. J Immunol (2020) 205:133-42. doi: 10.4049/jimmunol.2000156

10. Young KJ, Yang L, Phillips MJ, Zhang L. Donor-Lymphocyte Infusion Induces Transplantation Tolerance by Activating Systemic and Graft-Infiltrating Double-Negative Regulatory T Cells. Blood (2002) 100:3408-14. doi: 10.1182/blood-2002-01-0235

11. Zhang D, Yang W, Degauque N, Tian Y, Mikita A, Zheng XX. New Differentiation Pathway for Double-Negative Regulatory T Cells That Regulates the Magnitude of Immune Responses. Blood (2007) 109:4071-9. doi: 10.1182/blood-2006-10-050625

12. Li W, Tian Y, Li Z, Gao J, Shi W, Zhu J, et al. Ex Vivo Converted Double Negative T Cells Suppress Activated B Cells. Int Immunopharmacol (2014) 20:164-9. doi: 10.1016/j.intimp.2014.02.034

13. Tian D, Yang L, Wang S, Zhu Y, Shi W, Zhang C, et al. Double Negative T Cells Mediate Lag3-Dependent Antigen-Specific Protection in Allergic Asthma. Nat Commun (2019) 10:4246. doi: 10.1038/s41467-019-12243-0

14. Mitra A, Satelli A, Yan J, Xueqing X, Gagea M, Hunter CA, et al. IL-30 (Il27p28) Attenuates Liver Fibrosis Through Inducing NKG2D-rae1 Interaction Between NKT and Activated Hepatic Stellate Cells in Mice. HEPATOLOGY (2014) 60:2027-39. doi: 10.1002/hep.27392

15. Zingoni A, Ardolino M, Santoni A, Cerboni C. NKG2D and DNAM-1 Activating Receptors and Their Ligands in NK-T Cell Interactions: Role in the NK Cell-Mediated Negative Regulation of T Cell Responses. Front Immunol (2012) 3:408. doi: 10.3389/fimmu.2012.00408

16. Grau M, Valsesia S, Mafille J, Djebali S, Tomkowiak M, Mathieu AL, et al. Antigen-Induced But Not Innate Memory Cd8 T Cells Express NKG2D and Are Recruited to the Lung Parenchyma Upon Viral Infection. J Immunol (2018) 200:3635-46. doi: 10.4049/jimmunol.1701698

17. Cao G, Wang Q, Li G, Meng Z, Liu H, Tong J, et al. mTOR Inhibition Potentiates Cytotoxicity of Vgamma4 Gammadelta T Cells Via Up-Regulating NKG2D and TNF-Alpha. J Leukoc Biol (2016) 100:1181-9. doi: 10.1189/ jlb.5A0116-053RR

18. Dai Z, Turtle CJ, Booth GC, Riddell SR, Gooley TA, Stevens AM, et al. Normally Occurring NKG2D+CD4+ T Cells Are Immunosuppressive and 
Inversely Correlated With Disease Activity in Juvenile-Onset Lupus. J Exp Med (2009) 206:793-805. doi: 10.1084/jem.20081648

19. Jang YH, Choi JK, Jang YH, Moon SY, Lee WJ, Lee SJ, et al. Increased Blood Levels of NKG2D(+)CD4(+) T Cells in Patients With Alopecia Areata. J Am Acad Dermatol (2017) 76:151-3. doi: 10.1016/j.jaad.2016.07.056

20. Raulet DH. Roles of the NKG2D Immunoreceptor and Its Ligands. Nat Rev Immunol (2003) 3:781-90. doi: 10.1038/nri1199

21. Prajapati K, Perez C, Rojas L, Burke B, Guevara-Patino JA. Functions of NKG2D in CD8(+) T Cells: An Opportunity for Immunotherapy. Cell Mol Immunol (2018) 15:470-9. doi: 10.1038/cmi.2017.161

22. Wensveen FM, Lenartic M, Jelencic V, Lemmermann NA, Ten BA, Jonjic S, et al. NKG2D Induces Mcl-1 Expression and Mediates Survival of CD8 Memory T Cell Precursors Via Phosphatidylinositol 3-Kinase. J Immunol (2013) 191:1307-15. doi: 10.4049/jimmunol.1300670

23. Lutz MB, Kukutsch N, Ogilvie AL, Rossner S, Koch F, Romani N, et al. An Advanced Culture Method for Generating Large Quantities of Highly Pure Dendritic Cells From Mouse Bone Marrow. J Immunol Methods (1999) 223:77-92. doi: 10.1016/S0022-1759(98)00204-X

24. French SW, Lu JG. Piecemeal Necrosis is Due to the Immunologic Synapse Formation and Internalization of Intact TCR-MHC II Complexes by CD 4 T Cells. Exp Mol Pathol (2018) 105:150-2. doi: 10.1016/j.yexmp. 2018.07.004

25. Chowdhary VR, Krogman A, Tilahun AY, Alexander MP, David CS, Rajagopalan G. Concomitant Disruption of CD4 and CD8 Genes Facilitates the Development of Double Negative Alphabeta TCR(+) Peripheral T Cells That Respond Robustly to Staphylococcal Superantigen. J Immunol (2017) 198:4413-24. doi: 10.4049/jimmunol.1601991

26. Tong D, Zhang L, Ning F, Xu Y, Hu X, Shi Y. Contact-Dependent Delivery of IL-2 by Dendritic Cells to CD4 T Cells in the Contraction Phase Promotes Their Long-Term Survival. Protein Cell (2020) 11:108-23. doi: 10.1007/ s13238-019-00662-0

27. Cho KJ, Ishido S, Eisenlohr LC, Roche PA. Activation of Dendritic Cells Alters the Mechanism of MHC Class II Antigen Presentation to CD4 T Cells. J Immunol (2020) 204:1621-9. doi: 10.4049/jimmunol.1901234

28. Mason L, Koetsveld J, Trentelman J, Kaptein TM, Hoornstra D, Wagemakers A, et al. Borrelia Miyamotoi Activates Human Dendritic Cells and Elicits T Cell Responses. J Immunol (2020) 204:386-93. doi: 10.4049/jimmunol. 1801589
29. Granucci F, Vizzardelli C, Pavelka N, Feau S, Persico M, Virzi E, et al. Inducible IL-2 Production by Dendritic Cells Revealed by Global Gene Expression Analysis. Nat Immunol (2001) 2:882-8. doi: 10.1038/ni0901-882

30. Schartz NE, Chaput N, Taieb J, Bonnaventure P, Trebeden-Negre H, Terme M, et al. IL-2 Production by Dendritic Cells Is Not Critical for the Activation of Cognate and Innate Effectors in Draining Lymph Nodes. Eur J Immunol (2005) 35:2840-50. doi: 10.1002/eji.200425628

31. Kim J, Chang CK, Hayden T, Liu FC, Benjamin J, Hamerman JA, et al. The Activating Immunoreceptor NKG2D and Its Ligands Are Involved in Allograft Transplant Rejection. J Immunol (2007) 179:6416-20. doi: 10.4049/jimmunol.179.10.6416

32. Obeidy P, Sharland AF. NKG2D and its Ligands. Int J Biochem Cell Biol (2009) 41:2364-7. doi: 10.1016/j.biocel.2009.07.005

33. Diefenbach A, Jamieson AM, Liu SD, Shastri N, Raulet DH. Ligands for the Murine NKG2D Receptor: Expression by Tumor Cells and Activation of NK Cells and Macrophages. Nat Immunol (2000) 1:119-26. doi: 10.1038/77793

34. Nice TJ, Coscoy L, Raulet DH. Posttranslational Regulation of the NKG2D Ligand Mult1 in Response to Cell Stress. J Exp Med (2009) 206:287-98. doi: $10.1084 /$ jem. 20081335

35. Raju S, Kretzmer LZ, Koues OI, Payton JE, Oltz EM, Cashen A, et al. NKG2DNKG2D Ligand Interaction Inhibits the Outgrowth of Naturally Arising LowGrade B Cell Lymphoma In Vivo. J Immunol (2016) 196:4805-13. doi: 10.4049/jimmunol.1501982

36. Lenartic M, Jelencic V, Zafirova B, Ozanic M, Marecic V, Jurkovic S, et al. NKG2D Promotes B1a Cell Development and Protection Against Bacterial Infection. J Immunol (2017) 198:1531-42. doi: 10.4049/jimmunol.1600461

Conflict of Interest: The authors declare that the research was conducted in the absence of any commercial or financial relationships that could be construed as a potential conflict of interest.

Copyright (C) $2021 \mathrm{Hu}$, Zhang, Gao, Guo, Xun, Xiang, Cheng, Li and Zhu. This is an open-access article distributed under the terms of the Creative Commons Attribution License (CC BY). The use, distribution or reproduction in other forums is permitted, provided the original author(s) and the copyright owner(s) are credited and that the original publication in this journal is cited, in accordance with accepted academic practice. No use, distribution or reproduction is permitted which does not comply with these terms. 